\title{
An Animal Model Using Metallic Ions to Produce Autoimmune Nephritis
}

\author{
Roxana Ramírez-Sandoval, ${ }^{1}$ Nayeli Luévano-Rodríguez, ${ }^{1}$ Mayra Rodríguez-Rodríguez, \\ María Elena Pérez-Pérez, ${ }^{1}$ Sergio Saldívar-Elias, ${ }^{1}$ Reinaldo Gurrola-Carlos, ${ }^{2}$ \\ Esperanza Avalos-Díaz, ${ }^{1}$ Juan José Bollain-y-Goytia, ${ }^{1}$ and Rafael Herrera-Esparza ${ }^{1}$ \\ ${ }^{1}$ Laboratorios de Inmunología y Biología Molecular, UA Ciencias Biológicas, Universidad Autónoma de Zacatecas, \\ 98040 Zacatecas, ZAC, Mexico \\ ${ }^{2}$ Departamento de Patología, Universidad Autónoma de Durango, Campus Zacatecas, 98160 Zacatecas, ZAC, Mexico
}

Correspondence should be addressed to Rafael Herrera-Esparza; rafael.herreraesparza@gmail.com

Received 4 January 2015; Accepted 19 March 2015

Academic Editor: Kurt Blaser

Copyright (C) 2015 Roxana Ramírez-Sandoval et al. This is an open access article distributed under the Creative Commons Attribution License, which permits unrestricted use, distribution, and reproduction in any medium, provided the original work is properly cited.

\begin{abstract}
Autoimmune nephritis triggered by metallic ions was assessed in a Long-Evans rat model. The parameters evaluated included antinuclear autoantibody production, kidney damage mediated by immune complexes detected by immunofluorescence, and renal function tested by retention of nitrogen waste products and proteinuria. To accomplish our goal, the animals were treated with the following ionic metals: $\mathrm{HgCl}_{2}, \mathrm{CuSO}_{4}, \mathrm{AgNO}_{3}$, and $\mathrm{Pb}\left(\mathrm{NO}_{3}\right)_{2}$. A group without ionic metals was used as the control. The results of the present investigation demonstrated that metallic ions triggered antinuclear antibody production in $60 \%$ of animals, some of them with anti-DNA specificity. Furthermore, all animals treated with heavy metals developed toxic glomerulonephritis with immune complex deposition along the mesangium and membranes. These phenomena were accompanied by proteinuria and increased concentrations of urea. Based on these results, we conclude that metallic ions may induce experimental autoimmune nephritis.
\end{abstract}

\section{Introduction}

Autoimmunity induced by metallic ions was previously described in experimental animals and humans suffering from chronic intoxication by heavy metals. However, the pathogenic mechanisms are only partially understood. One possibility is that interactions between metallic ions and normal proteins may trigger a self-immune-response characterized by autoantibody production and cell hypersensitivity. A second possibility is that stereochemical alteration of normal proteins results in the exposition of cryptic self-epitopes or neoepitope formation capable of activating autoreactive clones. A third possibility is related to the increased production of apoptotic remains, resulting in externalization of intracellular antigens onto apoptotic cell membranes. Regardless of how autoantigens are produced, they are processed and presented via MHC molecules to the TCR, resulting in polyclonal activation and autoimmunity [1].

Different examples of autoimmune responses triggered by ionic metals have been reported. For instance, cadmium ions induce autoantibodies to laminin, chromium and platinum trigger antinuclear antibodies (ANA), copper induces antibodies against red blood cells, lithium is associated with ANA and antithyroid antibodies, gold stimulates the production of ANA with Ro specificity and antiplatelet autoantibodies, and finally silver salts induce antifibrillarin antibodies [2]. As a consequence, it is widely accepted that metallic ions are potential inducers of autoimmune responses.

The kidneys are sensitive organs involved in autoimmune diseases, especially lupus erythematosus. Thus, this interesting topic deserves our attention. Previous works demonstrated that exposure to mercury was associated with 
autoimmune nephritis accompanied by autoantibody production and increased levels of proinflammatory cytokines such as TNF $\alpha$, IL-1, and IFN $\gamma$. Similarly, animals that suffer contamination with mercury ions or their derivatives display membranous nephropathy [3-6].

In the present study, we induced autoimmune nephritis in inbred Long-Evans rats by intoxication with heavy metals; this model was chosen because other researchers previously reported nephrotoxicity in rats including Brown Norway (BN) and Sprague-Dawley; also lower doses of mercuric chloride administrated to outbreed Wistar rats resulted in renal toxicity [7]. We used inbred Long-Evans strains to maintain homozygosis; therefore, we observed in this particular strain high sensitivity to heavy metals injuries; therefore, this animal model was used to induce autoimmunity and we assessed antinuclear antibodies, kidney damage, and abnormalities in glomerular function. Main results of present work indicate that metallic ions can trigger glomerulonephritis associated with autoantibodies.

\section{Material and Methods}

2.1. Animals. Male Long-Evans rats that were 8 weeks of age with an average weight between 198 and $258 \mathrm{~g}$ were used for the present experiments. The animals were maintained under standard conditions at the animal facility unit of our research institute with free access to food and water. The animals were exposed to metallic ions by a weekly injection. Serum and urine samples were collected simultaneously with the weekly injections, and tissue biopsies were obtained at the end of the intoxication trial. The kidneys were collected immediately after sacrifice. Experiments were conducted according to the guidelines for ethical conduct in the care and use of animals developed by the American Psychological Association (APA) (http://www.apa.org/science/anguide.html).

2.2. Experimental Groups. Animals were grouped $(n=5)$ according to the treatments with metallic ions as follows: Group (I), the control group treated with $100 \mu \mathrm{L}$ of sterile $0.9 \% \mathrm{NaCl}$; Group (II) treated with $\mathrm{HgCl}_{2}(1.5 \mathrm{mg} / 100 \mathrm{~g}$ of weight); Group (III) treated with $\mathrm{CuSO}_{4}(3 \mathrm{mg} / 100 \mathrm{~g}$ of weight); Group (IV) treated with $\mathrm{AgNO}_{3}$ (3 mg/100 g of weight); and Group (V) treated with $\mathrm{Pb}\left(\mathrm{NO}_{3}\right)_{2}(6 \mathrm{mg} / 100 \mathrm{~g}$ of weight). The metallic ions were dissolved in distilled water and administered subcutaneously weekly over a period of 8 weeks. Urine and serum samples were obtained to determinate proteinuria and urea concentrations by conventional methods. At the end of the trial the animals were anesthetized with ether and sacrificed, followed by kidney excision. The organs were rinsed with PBS. One tissue fragment was included in Tissue-tek, frozen at $-20^{\circ} \mathrm{C}$, and then used for direct immunofluorescence. The other kidney fragment was fixed in $10 \%$ formalin and processed for $\mathrm{H} \& \mathrm{E}$ staining and immunohistochemistry.

2.3. Antinuclear Antibodies. Commercial slides containing HEp-2 cells (Immuno Concepts NA, Ltd, Sacramento, CA) were incubated for 30 minutes with serum diluted from $1: 80$ to $1: 1280$, followed by three times of PBS washing and a 30-minute incubation with FITC-labeled goat anti-rat polyvalent gamma globulin (IgG, IgA, and IgM; SAB3700662 Sigma). After another round of washing, the slides were mounted in glycerol-PBS and evaluated with fluorescence microscopy. And anti-DNA antibodies by immunofluorescence using Crithidia luciliae (Immuno Concepts NA, Ltd, Sacramento, CA). The fine specificity of sera samples was tested by ELISA against the following recombinant proteins: Ro60, La, and Sm/RNP (Euroimmun AG, Lübeck, Germany, and Orgentec Diagnostics GmbH, Mainz, Germany). Goat anti-rat polyvalent HRP-labeled anti-IgG and -IgM antibodies were used as the secondary antibodies (Sigma, SAB3700666-2MG).

2.4. Direct Immunofluorescence. A $4 \mu \mathrm{m}$ slice of renal tissue was obtained using cryosectioning. The tissues were rinsed in $0.15 \mathrm{M}$ PBS, and any possible immune depositions were detected after incubation with FITC-labeled goat anti-rat polyvalent gamma globulin (IgG, IgA, and IgM; SAB3700662 Sigma). After 30-minute incubation, the slides were rinsed, mounted in glycerol-PBS, and evaluated using fluorescent microscopy.

2.5. Immunohistochemistry. To investigate intracellular autoantigen exposition in the kidneys, the tissues were tagged with monoclonal antibodies against the follow ribonucleoproteins: Sm (Pierce MA5-13449), RNP (Pierce MA134962), Ro60 (Santa Cruz Biotechnology, sc-100844), and La (Mybiosource MBS533624) as follows. Slides containing $4 \mu \mathrm{m}$ sections of renal tissue were dewaxed, permeabilized, and washed three times with PBS. Endogenous peroxidase was blocked with $3 \%$ horse serum inactivated at $56^{\circ} \mathrm{C}$. After washing, the tissues were incubated for 1 hour with the monoclonal antibody diluted in $10 \%$ fetal calf serum/PBS according to the manufacturer's recommendations. The slides were washed with PBS and then incubated for 1 hour with HRP-labeled rabbit anti-mouse IgG. After washing, the color reaction was induced by $3,3^{\prime}$-diaminobenzidine- $0.06 \% \mathrm{H}_{2} \mathrm{O}_{2}$ (Sigma, Catalog number A9044), and finally the reaction was stopped with $2 \mathrm{~N}$ sulfuric acid. Assays were performed in duplicate and evaluated by two observers using a light microscope. The intensity of the color reaction obtained from kidneys by immunohistochemistry displays an intensity signal which was expressed in pixels and was analyzed with the software Image-Pro Plus Version 7.0. (Media Cybernetics, USA).

2.6. Double Fluorescence Labeling Assays. To assess the presence of intracellular antigens on apoptotic glomerular membranes, we colocalized the possible target proteins using a double fluorescence assay. Briefly, the autoantigens were tagged in red via 120-minute incubation with monoclonal anti-Sm and anti-RNP, anti-Ro60, or anti-La antibody. Next, the samples were incubated for 120 minutes with goat anti-mouse Texas red-labeled antibody (IgG-TR) (Catalog number sc-2781. Santa Cruz Biotechnology, Inc. Santa Cruz, CA). Apoptotic membranes were stained in green with FITC Annexin V (BD Pharmigen) (this assay is based on the property of cells to lose membrane asymmetry in 
TABLE 1: Major histological findings in animals intoxicated with metal ions.

\begin{tabular}{ll}
\hline Control & Glomeruli conserved, tubules, interstice, and blood vessels normal \\
\hline $\mathrm{AgNO}_{3}$ & $\begin{array}{l}\text { Glomeruli with mesangial moderate hypercellularity, interstitial lymphocyte infiltration, congested blood } \\
\text { vessels, edema of convoluted tubules, and the presence of proteinaceous material }\end{array}$ \\
\hline $\mathrm{CuSO}_{4}$ & $\begin{array}{l}\text { Glomerular size increased as Bowman space decreased; podocytes with enlarged volume, thickened } \\
\text { membranes, and discrete lymphocytic infiltrates, tubular edema with the luminal presence of proteinaceous } \\
\text { material, and diffuse vascular congestion }\end{array}$ \\
\hline $\mathrm{HgCl}_{2}$ & $\begin{array}{l}\text { Glomerulus and Bowman space enlarged, mesangial cell proliferation, podocytes with increased volume, } \\
\text { increase in membrane thickness, interstitium with inflammatory infiltrate of neutrophils, and tubules with } \\
\text { epithelial edema and presence of acidophilus material }\end{array}$ \\
\hline $\mathrm{Pb}\left(\mathrm{NO}_{3}\right)_{2}$ & $\begin{array}{l}\text { Glomeruli with slight increase in size, increased Bowman space, increased membrane thickness, discrete } \\
\text { inflammatory infiltrate, and tubular edema }\end{array}$ \\
\hline
\end{tabular}

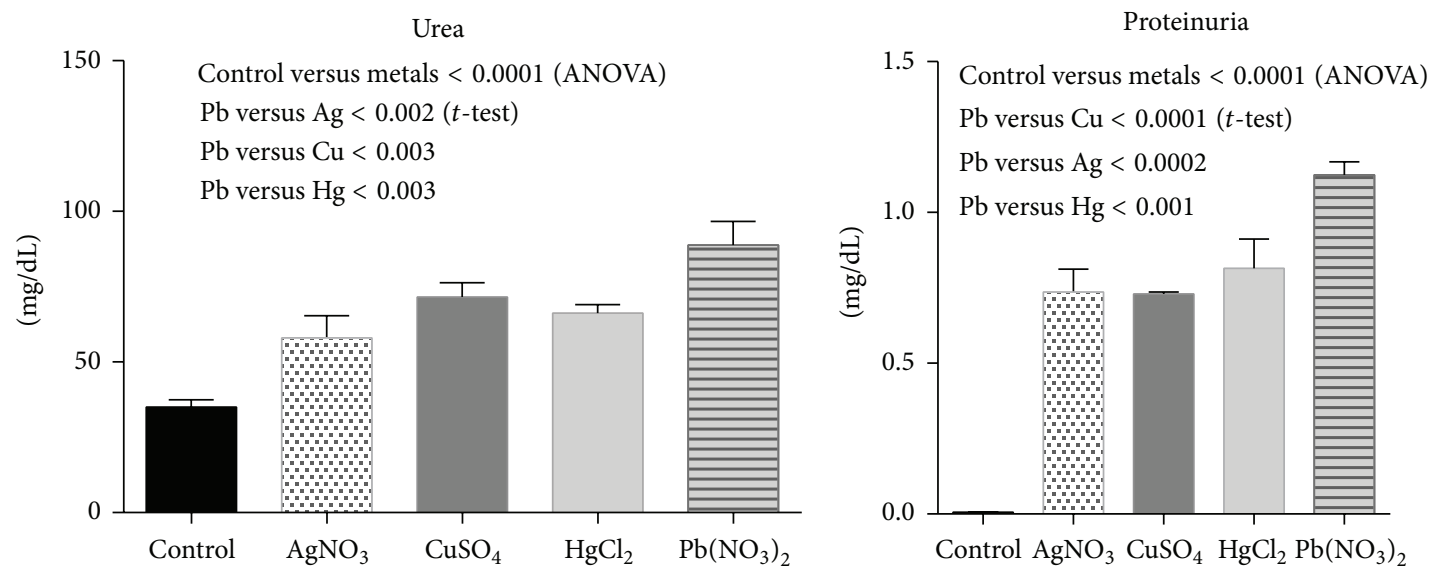

FIGURE 1: Urea and proteinuria determined at the beginning of the trial (control) and at the end of the intoxication trial. The graphs show the mean and standard deviation (SD).

the early phases of apoptosis because annexin $\mathrm{V}$ is a calciumdependent phospholipid binding protein that binds with high affinity to phosphatidylserine). The tissues were rinsed with $1 \mathrm{x}$ binding buffer and then incubated for 15 minutes with $10 \mu \mathrm{g}$ of FITC-labeled recombinant annexin, followed by PBS washing. Finally, the slides were counterstained with DAPI, mounted, and evaluated under a fluorescence microscope using the appropriate filters for the dyes.

2.7. Podocyte Involvement. To investigate whether podocytes were affected by metallic ions, the tissues were blocked with $3 \%$ fetal bovine serum in PBS for 30 minutes and incubated for one hour with monoclonal anti-WT1 antibody (Catalog number sc-7385 Santa Cruz, Biotechnology Inc., Santa Cruz, CA) 1:100 in 10\% FBS-PBS. After washing with PBS, the presence of the bound antibody was identified with goat anti-mouse IgG-TR. Additionally, following the washes some slides were counterstained with $4^{\prime}, 6$-diamidino2-phenylindole (DAPI). Finally, the slides were mounted and examined using fluorescent microscopy [8].

2.8. Statistical Analyses. The data were processed using nonparametric statistics (ANOVA and $t$-test) and chi-square test using Graph Pad Prism version 6.0 Software. A $P$ value $<0.05$ was considered statistically significant.

\section{Results}

3.1. Kidney Pathology. The group of control animals did not develop any renal histology abnormalities. In contrast, the kidneys of animals treated with metallic ions developed tubular degeneration, glomerular swelling, and cell hypertrophy at the end of the trial. Furthermore, the urinary space was enhanced as a consequence of the glomerular atrophy, and many samples exhibited acute tubular edema and glomerular changes characterized by glomerular inflammation in varying degrees (Table 1).

The control group maintained normal renal function without proteinuria. The animals injected with different metallic ions developed renal dysfunction manifested by nitrogen waste product retention in all animals and in 50\% of the animals display proteinuria at the second week but at the end of the trial all animals display proteinuria (Figure 1).

3.2. Autoantibody Production. Most of the animals displayed negative ANA titers at the beginning of the trial; however, all sera collected from animals treated with metallic ions tested positive for ANA determination four weeks after treatment, and the ANA titers increased at the end of the trial, and most of the ANA exhibited a cytoplasmic and speckled pattern. An interesting finding was that rats treated 


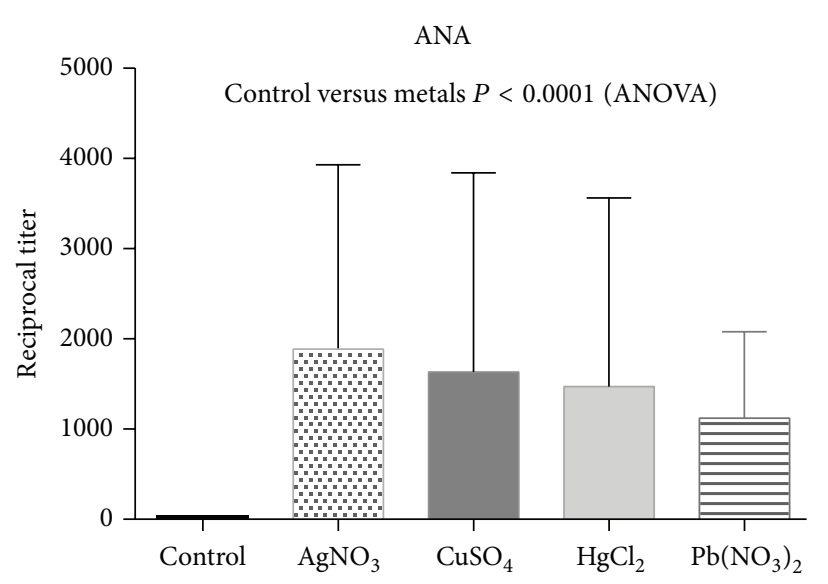

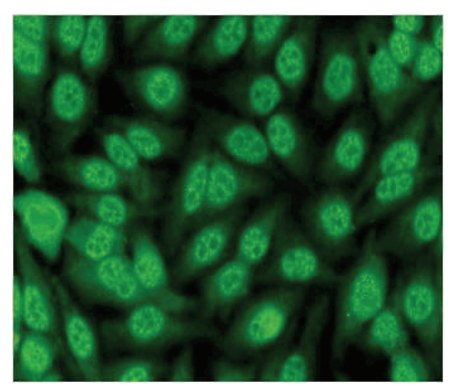

(A)

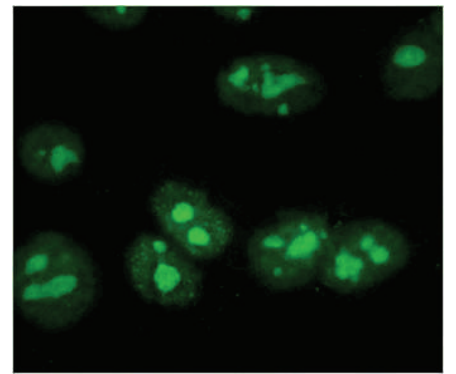

(C)

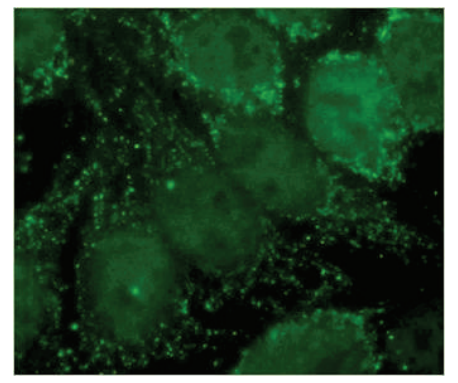

(E)

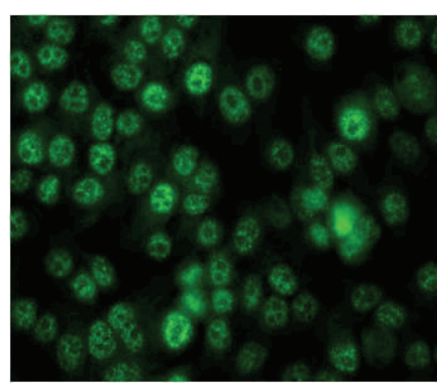

(B)

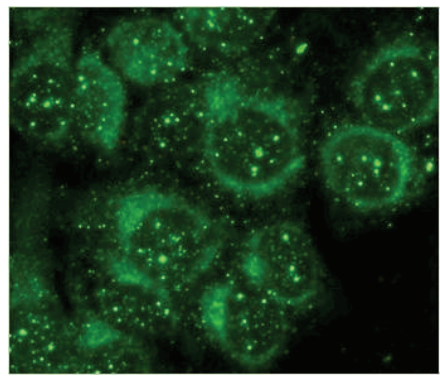

(D)

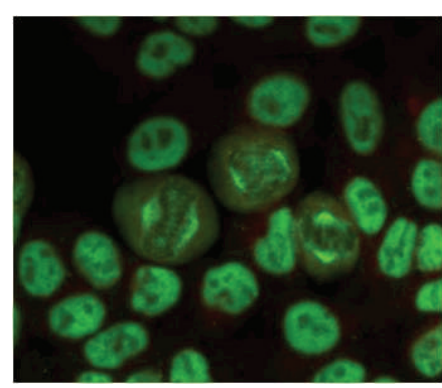

(F)

(a)

(b)

FIGURE 2: Indirect immunofluorescence assay graphs. (a) Antinuclear antibody (ANA) reciprocal titers using HEp-2 cells. The graphs show the mean and standard deviation (SD) and frequency of fluorescent patterns. And below is a graph showing the frequency of fluorescent patterns. On (b) different representative examples of ANA patterns: (A) nuclear speckled and cytoplasmic, (B) nuclear speckled, (C) nucleolar, (D) nuclear dots, (E) cytoplasmic, and (F) mitotic cells with staining of the nuclear mitotic apparatus.

with mercury developed anti-nucleoli antibodies (Figure 2). Anti-La antibodies were ubiquitously present in all groups treated with different metallic ions, while anti-DNA and antiSm antibodies were ubiquitously present except in animals treated with $\mathrm{HgCl}_{2}$ (Figure 3).

3.3. Immune Complexes at the Glomerular Level. A total of $60 \%$ of treated animals showed localization of immune complexes (IC) in their kidneys. These complexes were composed of IgG in complex with antigens from mesangium and/or membranes. This finding was common in different groups of animals treated with different metals; however, the IC trapping in the glomeruli of animals treated with $\mathrm{AgNO}_{3}$ and $\mathrm{Pb}\left(\mathrm{NO}_{3}\right)_{2}$ was remarkable. In spite of the fact that immune complex deposition was demonstrated at glomerular level only in the $60 \%$ of animals, the renal damage was evident by histopathology in all animals treated with metallic ions; furthermore, all intoxicated animals exhibited increased levels of urea and proteinuria and positive antinuclear antibodies or immune complex immune deposition at tubuli regardless of the metallic ion used in the trial (Figure 4).

3.4. Renal Autoantigen. Two assays were performed to assess the expression and externalization effect induced by metals on the exposure of Sm, RNP, Ro, and La autoantigens on apoptotic membranes of glomerular and tubular cells: immunohistochemistry and double fluorescence. (a) All ribonucleoproteins were strongly expressed following intoxication with all tested metallic ions (Figures 5 and 6), whereas the Ro antigen was detected in animals treated with $\mathrm{AgNO}_{3}$ and $\mathrm{Pb}\left(\mathrm{NO}_{3}\right)_{2}$ and the $\mathrm{Sm}$ ribonucleoprotein was overexpressed in animals treated with $\mathrm{CuSO}_{4}$ and $\mathrm{AgNO}_{3}$. (b) Interestingly, the Ro and La autoantigens were distributed on the apoptotic membranes of mesangial cells and podocytes (Figures 7 and 8). Autoantigens are normally expressed inside of tubular and glomerular cells rather than externalized onto apoptotic membranes, as was the case for the animals treated with heavy metals (Figure 9). This type of apoptotic process 

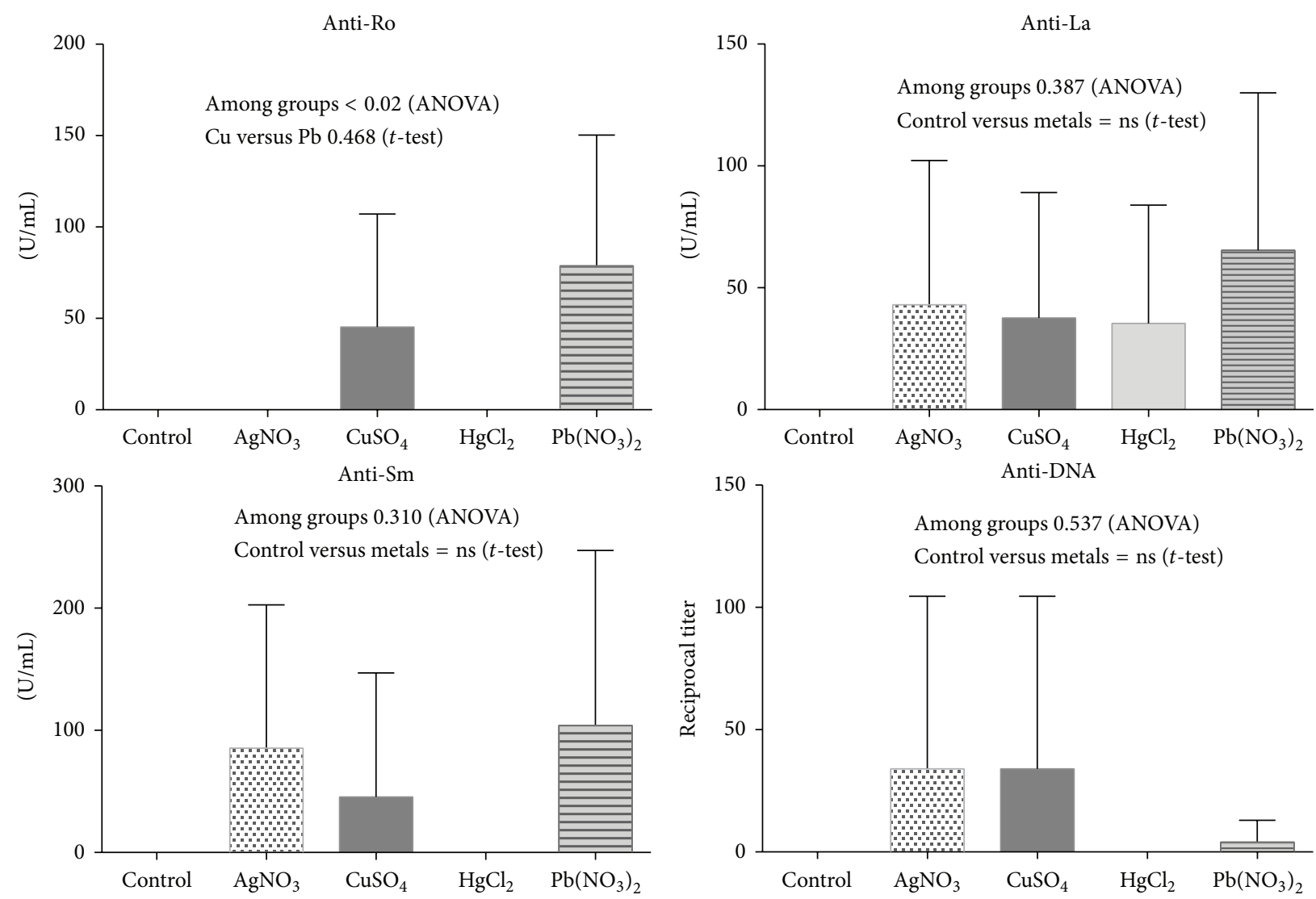

FIGURE 3: Antinuclear antibody specificity determined by ELISA (anti-Ro, anti-La, and anti-Sm) and the anti-DNA titers determined by indirect immunofluorescence with Crithidia luciliae. The graphs show the mean and SD.

involves the podocytes, as shown in the podocyte marker WT1 (Figure 10).

\section{Discussion}

Exposure to metal ions is the result of human activities such as mining, industrial processes, and other activities; this produce contamination of water sources, food, and consequently the inadvertent exposure or accidental contamination with heavy metals may affect humans or animals which can develop autoimmunity. The experimental models of autoimmunity induced by metal ions are important because they allow us to explore the pathophysiological mechanisms that trigger autoimmunity, and using this approach makes it possible to clarify clinically manifestations observed in human beings who are accidentally or inadvertently exposed to these pollutants.

The present study was undertaken to address the possible role of metallic ions in autoimmunity. Autoimmunity was triggered using an experimental rat model based on treatment with different heavy metals. The main findings can be summarized as follows. (1) Metallic ions such as mercury, lead, silver, and copper trigger the production of antinuclear antibodies. (2) The animals develop kidney damage demonstrated by proteinuria and urea retention. (3) Morphology changes including glomerular swelling and tubular degeneration were induced by the metals. (4) Immune glomerular damage was mediated by immune complexes. Taken together, we can conclude that heavy metals are capable of triggering autoimmune nephritis.

Experimental nephritis induced by mercury chloride [9], cadmium, and gold was previously reported [10-12]; additionally other reports suggest that lead might alter the clearance of immune complexes at the mesangial level [13]. In current investigation doses reported by other authors were used in the trial $[14,15]$, and our results agree with previous reports demonstrating that metallic ions may induce autoantibodies in serum and cause immune complex deposition along the mesangium and glomerular base membranes [16]. The original contribution of the present work demonstrates that the overexpression of intracellular ribonucleoproteins such as Ro, La, RNP, and Sm is caused by apoptosis; therefore, based on the results of our double fluorescence assays, we demonstrate that intracellular antigens are externalized onto the surface of apoptotic membranes and the externalization of autoantigen might contribute to disrupt the tolerance. Another original observation is that the toxic effect of ionic metals decreases the podocyte number and also modifies its diaphragm function resulting in proteinuria; this is a new finding that was not previously reported. Another important observation of this study indicates that homozygous animals 

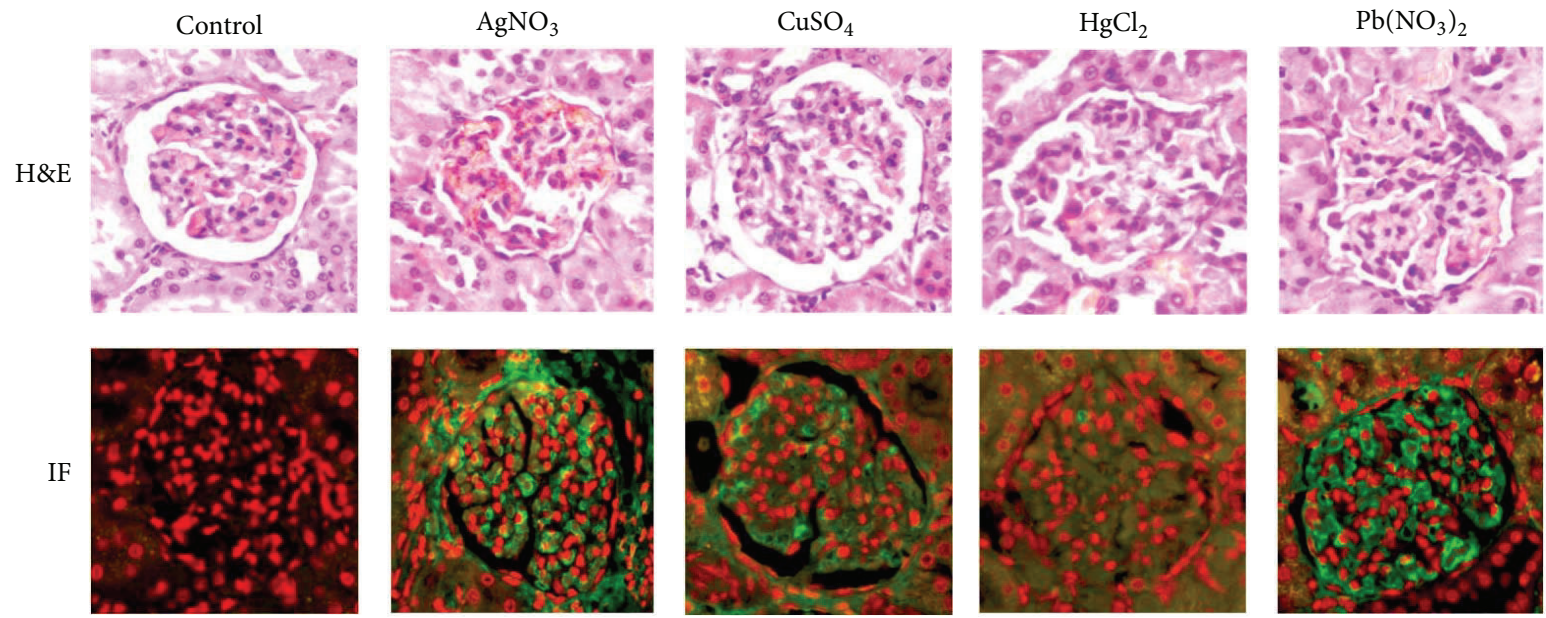

Figure 4: Renal histopathology. The top panel shows the control at the beginning of the trial and histology four weeks after each treatment by hematoxylin and eosin (H\&E) staining. The bottom panel displays the glomerular direct immunofluorescence (IF) in the basal condition (control) and at the end of the trial. The immunofluorescence shows deposition of IgG in the glomerulus. Nuclei were counterstained using propidium iodide.
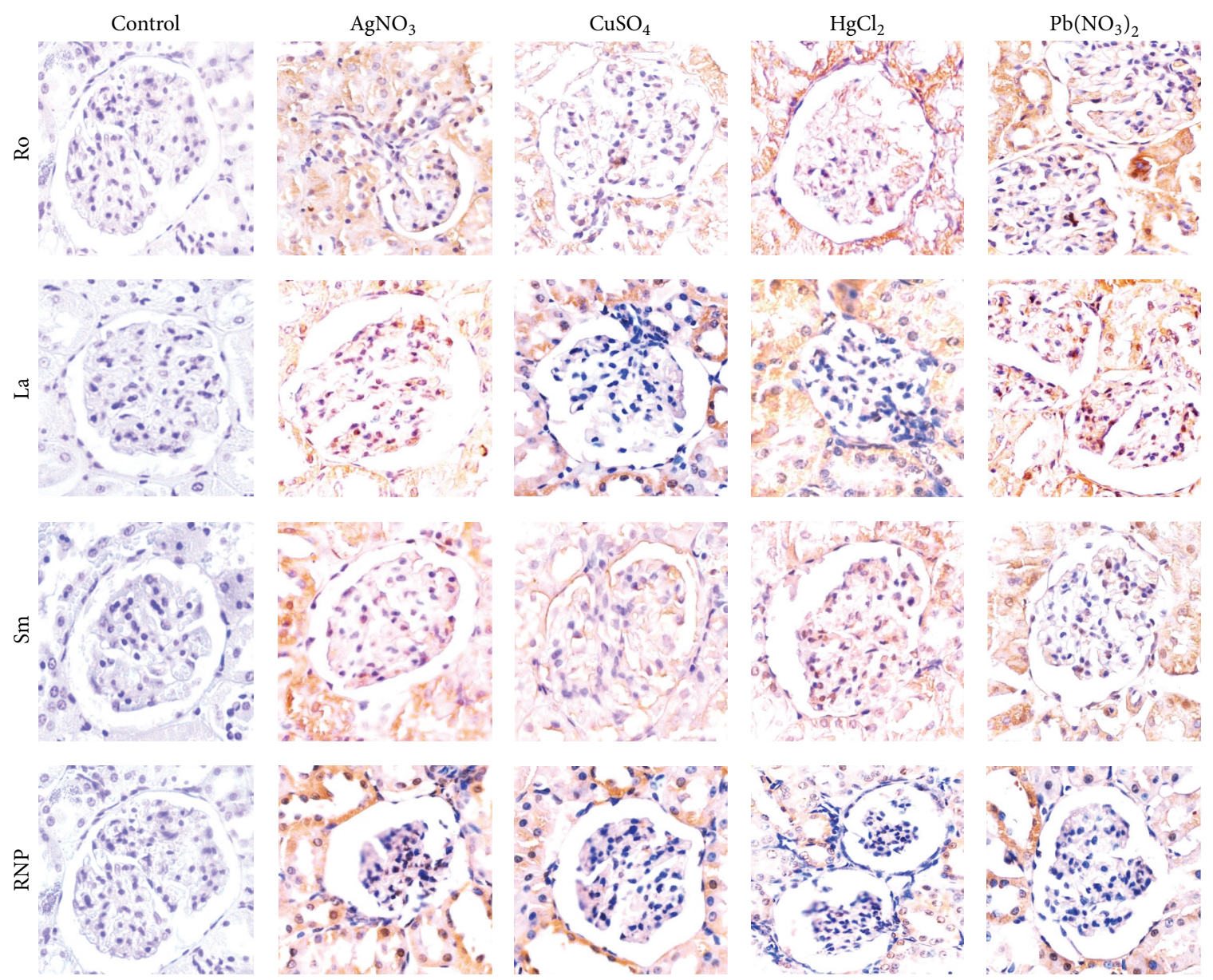

FIGURE 5: Immunohistochemistry of kidneys demonstrating the overexpression of ribonucleoproteins induced by heavy metal salts. Note that at the beginning of the trial (control), the expression is faint or absent, whereas at the end of the intoxication trial, ribonucleoprotein expression notably increases. 
Ro60
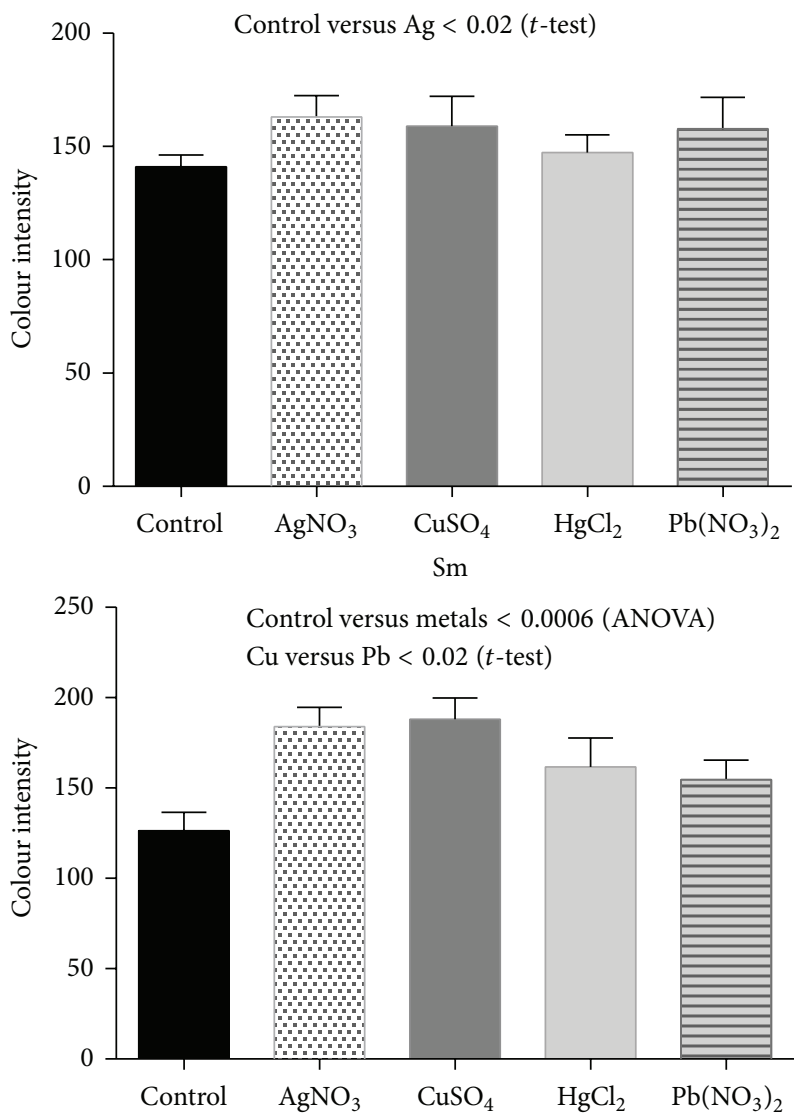

La
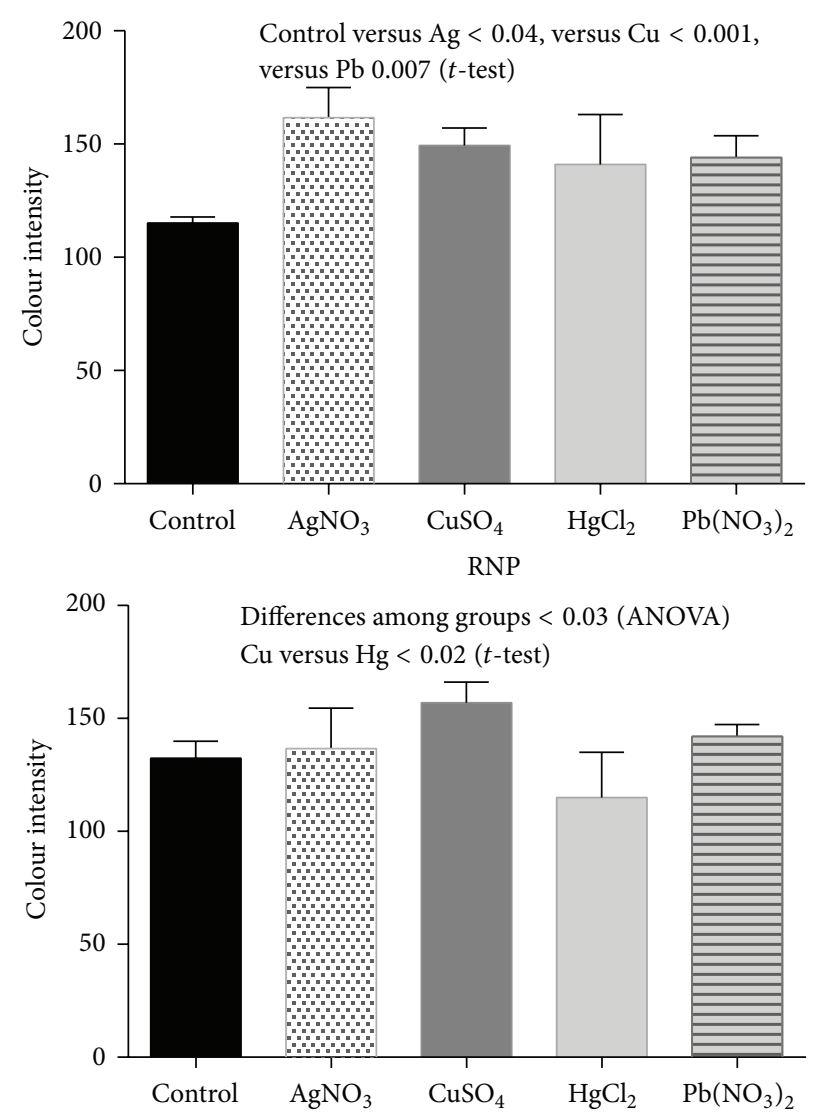

FIGURE 6: Ribonucleoprotein expression by immunohistochemistry of kidneys. The graphs (mean and SD) express the intensity of the color reaction obtained demonstrating the overexpression of some ribonucleoproteins induced by heavy metal salts.

are more susceptible to the nephrotoxic effects of metal ions; in this sense we previously found (unpublished observations) that heterozygous animals showed reduced susceptibility to renal injury by metal salts. The biggest limitation is the small number of animals included in each experimental group, which does not rule conceptual observation that metal salts induce apoptosis, helping to outsource autoantigens which triggers autoimmunity that favors the in situ immune complex formation which promotes renal failure and proteinuria.

In addition to the acute toxic effect of metallic ions on glomerular and tubular cells, it appears that subacute intoxication induces an autoimmune process in the kidneys. The mechanism responsible for this phenomenon that modifies the immune tolerance is still under investigation.

The effects of metallic ions on the immune response can be demarcated in at least two aspects. First, the metallic salts directly affect the conformation of proteins, resulting in autoantigen production; and, second, the adjuvant effect on the immune cells induces polyclonal cell activation. Both possibilities are mutual but not exclusive. A third factor involved in immunogenicity is the conformational changes that directly cause the metal ions on protein; so, it is important to understand that the metal binding sites on proteins are diverse and involve factors such as geometries, ligands, and metal preferences for certain protein domains. Nevertheless, metals commonly affect the highly hydrophobic centers [17]. Proteins with cysteine or histidine residues are modified by metal bonding and such interactions disrupt disulfide bonds or salt bridges. This type of disruption results in conformational changes in the secondary and tertiary structures, which can modify protein properties. Moreover, these stereochemical changes can expose cryptic antigens or induce the formation of neoantigens, resulting in better accommodation of "antigenic peptides" inside class II molecules of antigen presenting cells. These changes, together with the stimulation of autoimmune repertoires, render a breakdown of immune tolerance.

To predict the residues of autoantigens that are susceptible to metal binding, the Uniprot $\mathrm{KB} /$ Swiss-Prot data bank and the NCBI graphical sequence viewer were used to analyze metal-ion dependent adhesion sites (MIDAS) in the Ro60, La, Sm and RNP ribonucleoproteins. The Ro60 ribonucleoprotein (Uniprot KB/Swiss-Prot: P10155.2) displayed three binding sites at positions 378 , and 380 (serine), and 445 (threonine), suggesting that there is a molecular basis to assume that Ro60 can be modified by metal bonding (Table 2). Thus, modification of its behavior as an autoantigen is theoretically possible based on our findings of the presence of anti-Ro antibodies in the serum and deposited along the glomeruli of experimental animals. 


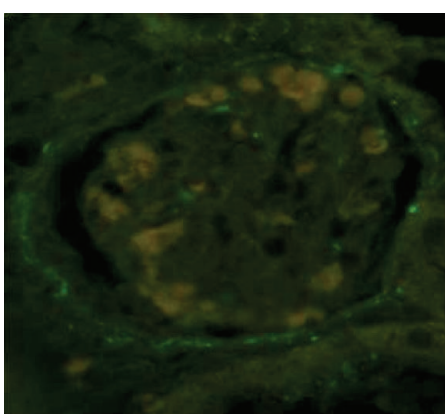

(a)

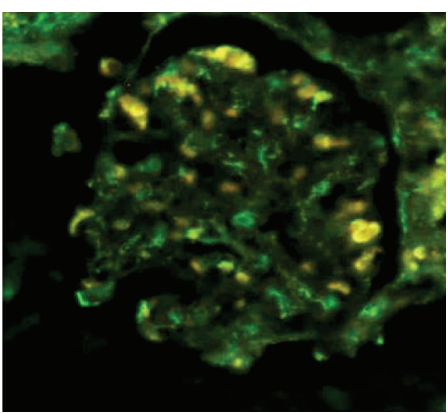

(d)

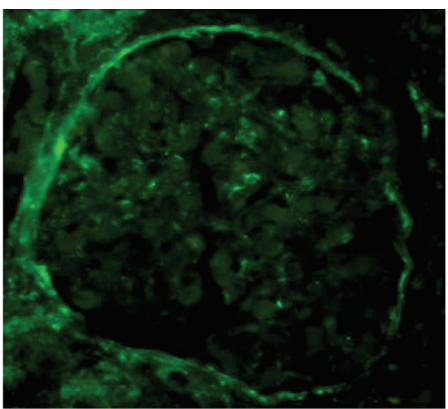

(g)

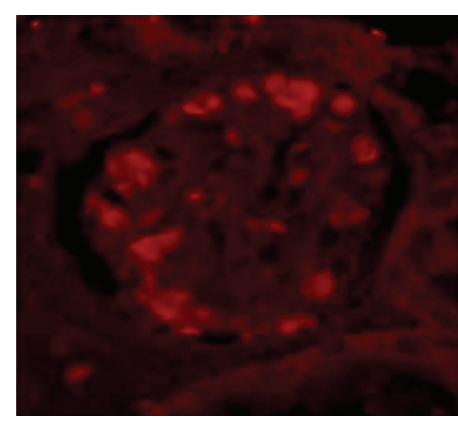

(b)

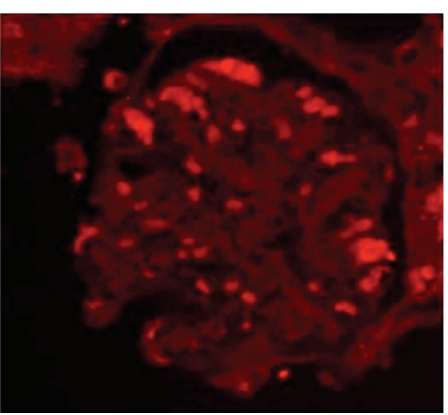

(e)

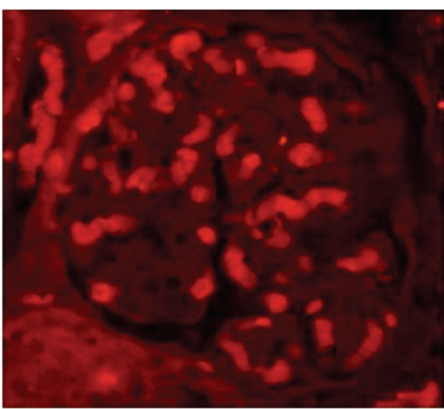

(h)

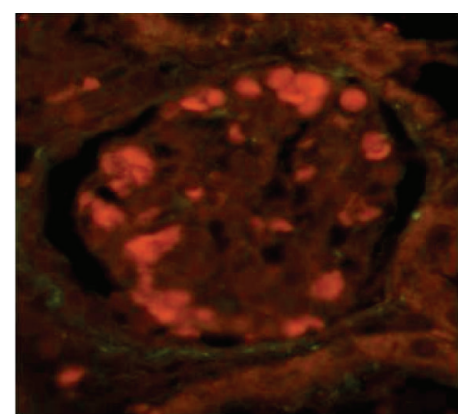

(c)

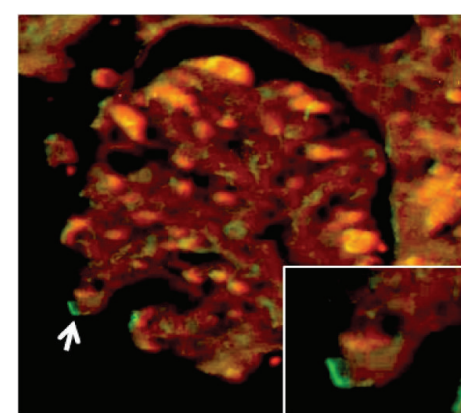

(f)

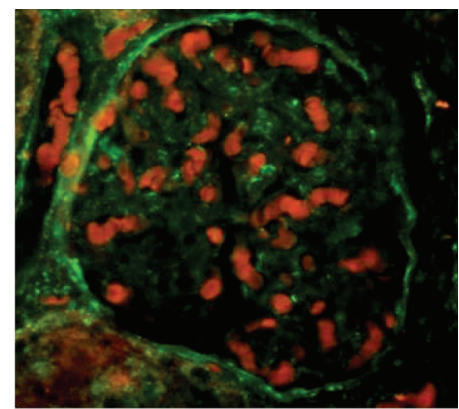

(i)

FIGURE 7: Double fluorescence assay showing apoptotic membranes of glomerular cells with annexin stained in green (a, d, and g) and intracellular autoantigens stained by Texas red (b, e, and h). The overlap merge is shown on the right (c, $f$, and $i)$. In the upper panel (a, b, and c), a control without metallic ions is shown, characterized by the absence of annexin and the faint presence of intracellular Ro protein. The sample in the middle panel ( $\mathrm{d}, \mathrm{e}$, and $\mathrm{f}$ ) was collected from an animal treated with $\mathrm{CuSO}_{4}$ and shows in the overlap fine linear traces in green of apoptotic membranes of podocytes (arrow and the square magnification) close to the translocated Ro autoantigens. The inferior panel corresponds to an experimental animal treated with $\mathrm{AgNO}_{3}$. Interestingly, annexin staining is broadly distributed along the membranes of the Bowman capsule and mesangial area coincident with the Sm ribonucleoprotein.

In contrast, the La, RNP, and Sm ribonucleoproteins did not display any MIDAS; however, this negative prediction did not rule out the possibility of stereochemical modification through interaction with $-\mathrm{SH}$ and carboxylate groups (which result in protein denaturation) as another potential source of antigenic peptides.

Metallic ions directly affect the immune system by working like an adjuvant. It is well known that the administration of subtoxic doses of mercury and other metals induces polyclonal activation of lymphocytes, yielding highly specific autoantibodies $[3,18]$.

In present work the cellular pathway involved in autoimmunity elicited by mercury salts encompasses endosomal
TLR signaling; in turn, this signaling stimulates transcription factor NF-kB and promotes the transcription of the pro-IL$1 \mathrm{~B}$ and IL- 6 genes. Then, pro-IL-1B is activated by caspase 1 at the inflammasome, and both cytokines promote autoimmunity [19-21]. Additionally, the lymphocyte activation gene3 (LAG-3) is an important regulator of autoimmunity in response to mercury [22].

\section{Conclusions}

In conclusion, this study focused on the analysis of environmentally induced autoimmunity using an animal model. Based on the present findings, we can suggest that metallic 


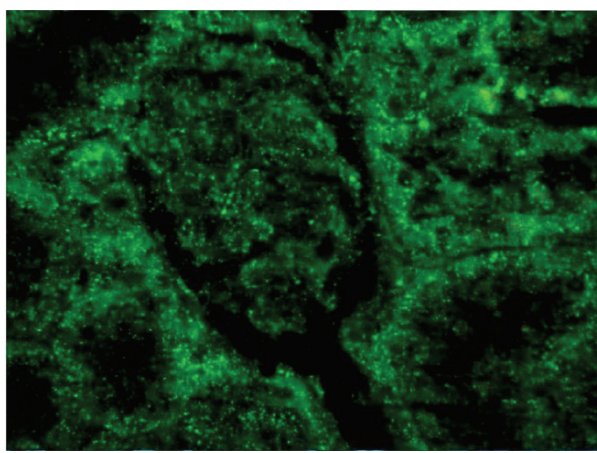

(a)

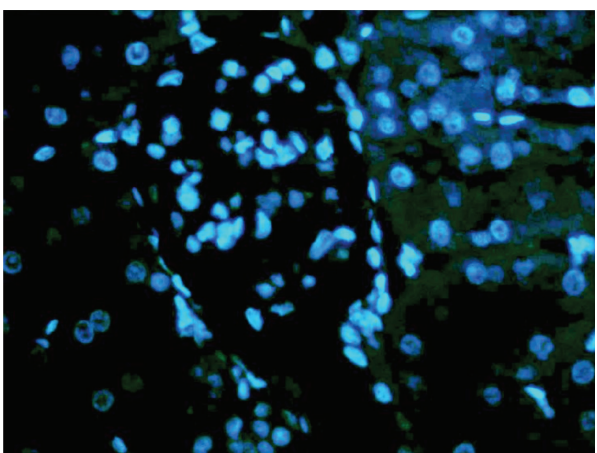

(c)

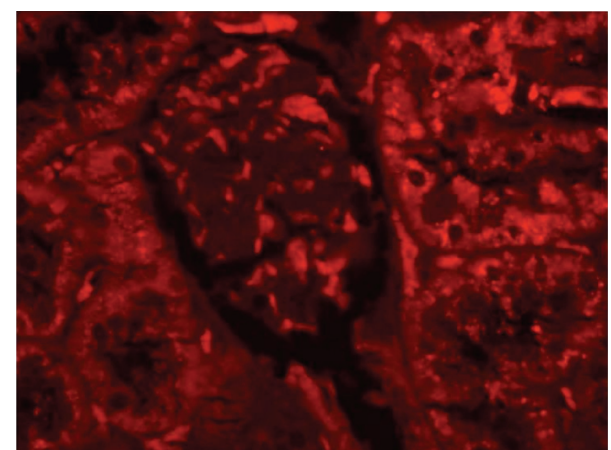

(b)

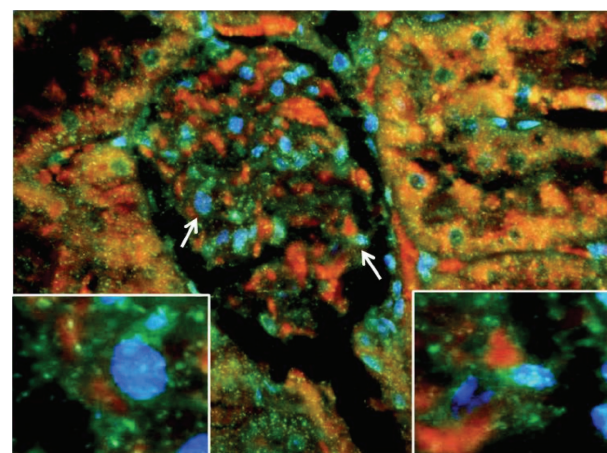

(d)

FIGURE 8: Double fluorescence assay in an animal treated with $\mathrm{CuSO}_{4}$ showing (a) a glomerulus stained in green by FITC-annexin localized to the apoptotic membranes, (b) La ribonucleoprotein stained by Texas red, (c) glomerulus nuclei stained in blue by DAPI, (d) merging image which shows colocalization of La/annexin; the arrows are representative examples of fields analyzed for colocalization of annexin (green) and La ribonucleoprotein (red) onto apoptotic membranes. The squares correspond to magnification areas pointed by arrows.

TABLE 2: Ro60 ribonucleoprotein analyzed using the NCBI graphical sequence viewer displaying the three metal-ion dependent adhesion sites (MIDAS) at positions 378, and 380 (serine), and 445 (threonine) (UniProtKB/Swiss-Prot: P10155.2).

\begin{tabular}{|c|c|c|c|c|c|}
\hline \multicolumn{6}{|c|}{ P10155[455], 60 kDa SS-A/Ro ribonucleoprotein, Homo sapiens } \\
\hline 10 & 20 & 30 & 40 & $5 \underline{0}$ & $6 \underline{0}$ \\
\hline MEESVNQMQP & LNEKQIANSQ & DGYVWQVTDM & NRLHRFLCFG & SEGGTYYIKE & QKLGLENAE $\bar{A}$ \\
\hline $7 \underline{0}$ & $8 \underline{0}$ & $9 \underline{0}$ & $10 \underline{0}$ & $11 \underline{0}$ & $12 \underline{0}$ \\
\hline LIRLIEDGRG $\bar{G}$ & CEVIQEIKSF & SQEGRTTKQE & PMLFALAICS & QCSDISTKQA & AFKAVSEVCR \\
\hline $13 \underline{0}$ & $14 \underline{0}$ & $15 \underline{0}$ & $16 \underline{0}$ & $17 \underline{0}$ & $18 \underline{0}$ \\
\hline IPTHLFTFIQ & FKKDLKESMK & 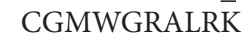 & AIADWYNEKG $\bar{G}$ & GMALALAVTK & YKQRNGWSHK \\
\hline 190 & 200 & 210 & 220 & 230 & 240 \\
\hline DLLRLSHLK $\bar{P}$ & SSEGLAIVTK & YITKGWKEVH̄ & ELYKEKALSV & ETEKLLKYLE & AVEKVKRTRD \\
\hline $25 \underline{0}$ & $26 \underline{0}$ & $27 \underline{0}$ & $28 \underline{0}$ & $29 \underline{0}$ & $30 \underline{0}$ \\
\hline ELEVIHLIEE & HRLVREHLLT & NHLKSKEVWK & ALLQEMPLTĀ & LLRNLGKMTĀ & NSVLEPGNSE \\
\hline 310 & 320 & 330 & 340 & 350 & 360 \\
\hline VSLVCEKLCN & EKLLKKARIH̄ & PFHILIALET & YKTGHGLRGK $\bar{K}$ & LKWRPDEEIL & KALDAAFYKT \\
\hline 370 & 380 & 390 & 400 & 410 & $42 \underline{0}$ \\
\hline FKTVEPTGKR & FLLAVDVSAS & MNQRVLGSIL & NASTVAAAMC & MVVTRTEKDS & YVVAFSDEMV \\
\hline $43 \underline{0}$ & $44 \underline{0}$ & $45 \underline{0}$ & $46 \underline{0}$ & $47 \underline{0}$ & $48 \underline{0}$ \\
\hline PCPVTTDMTL & QQVLMAMSQ̄I & PAGGTDCSLP & MIWAQKTNTP & ADVFIVFTDN $\bar{N}$ & ETFAGGVHPA \\
\hline 490 & 500 & 510 & 520 & 530 & \\
\hline IALREYRKKM & DIPAKLIVCḠ & MTSNGFTIAD & PDDRGMLDMC & GFDTGALDVI & RNFTLDMI \\
\hline \multicolumn{6}{|c|}{ Divalent metal cation } \\
\hline
\end{tabular}


Ro
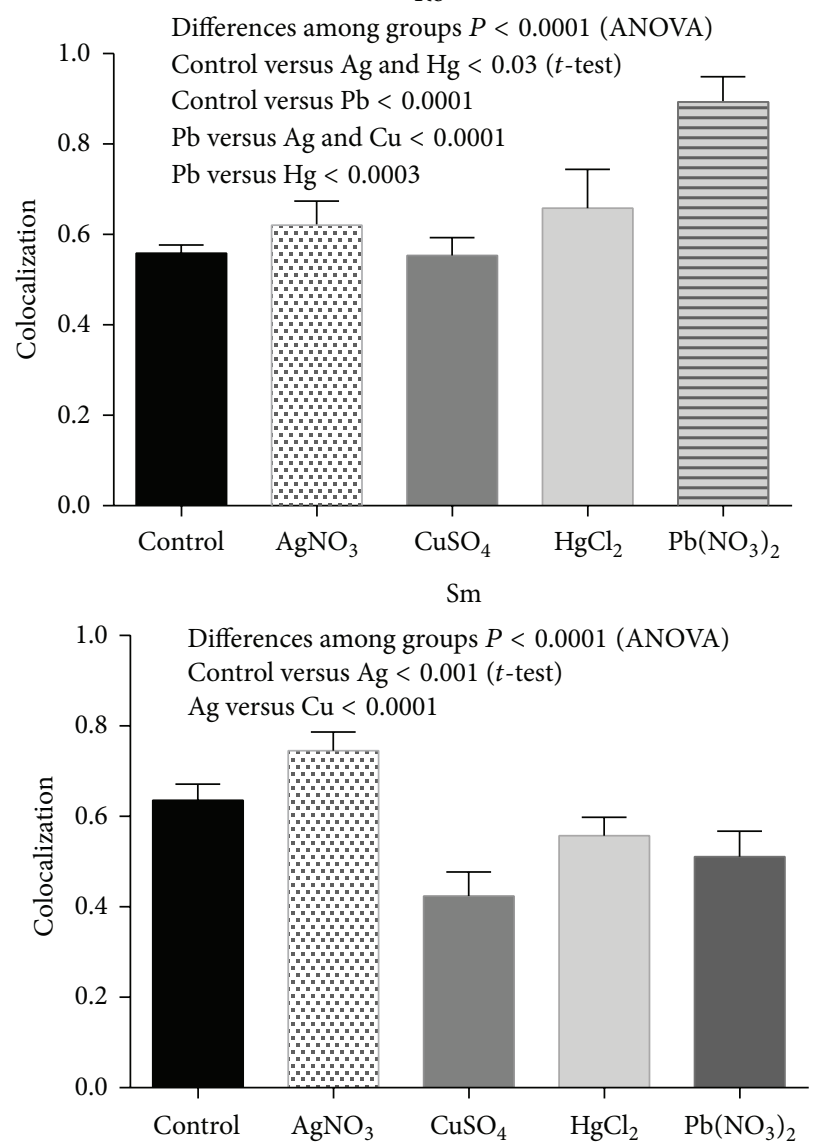

La
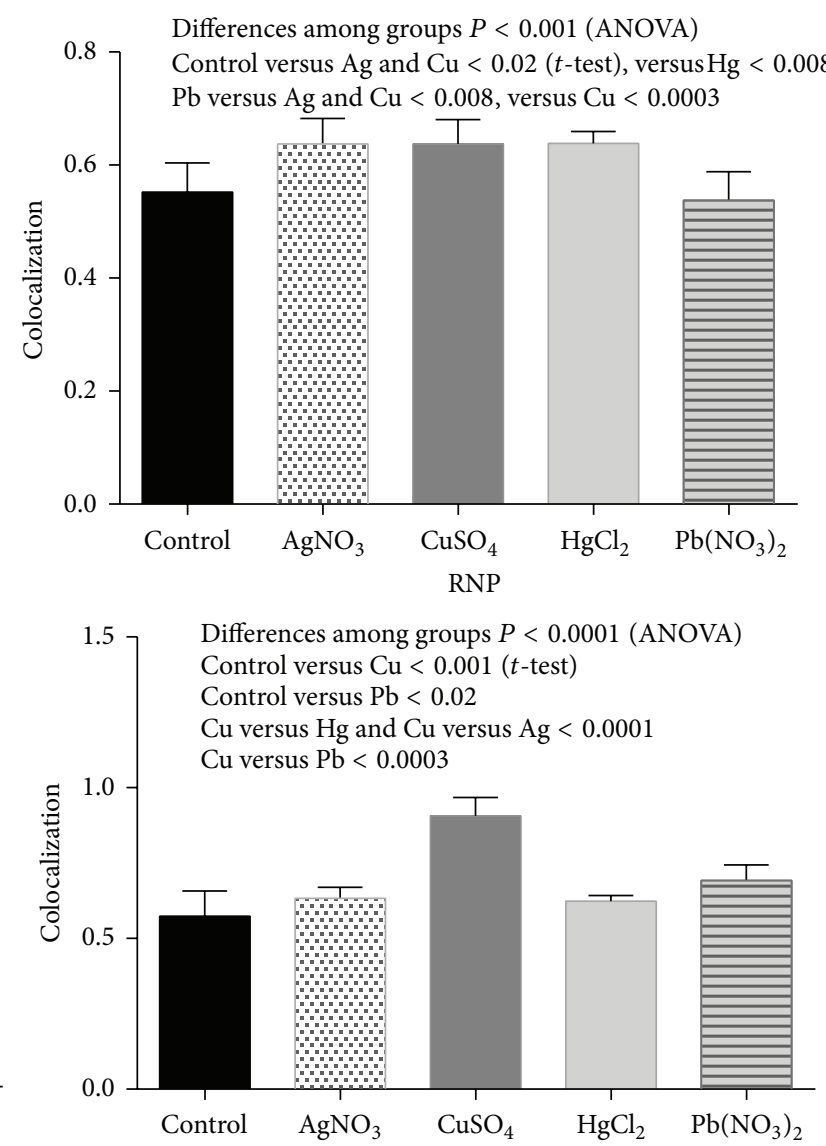

FIGURE 9: Colocalization analysis graphs (mean and SD) of ribonucleoproteins and apoptotic membranes (annexin) induced by heavy metal salts.

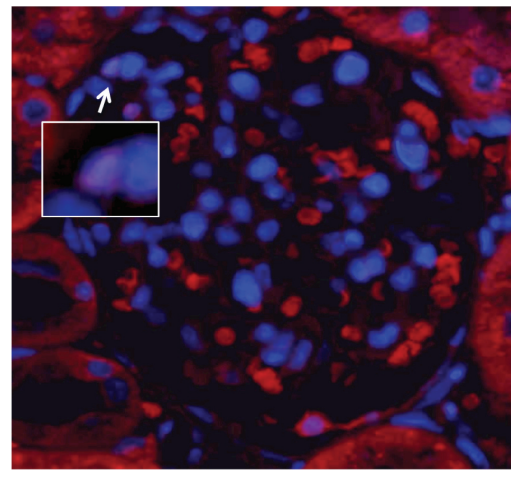

(a)

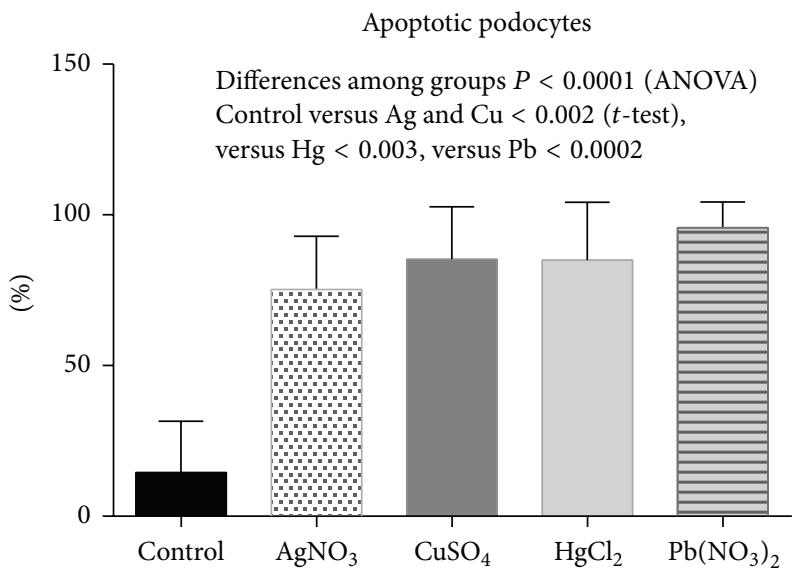

(b)

FIGURE 10: (a) Glomerulus showing podocytes tagged by WT1 in pink (arrow): the square corresponds to a magnified podocyte, nuclei stained in blue by DAPI. On (b) a graph showing the percent of apoptotic podocytes by metallic ions. 
ions induce autoreactive clones that trigger autoantibody production against intracellular ribonucleoproteins. These ribonucleoproteins are then exposed on apoptotic membranes, enabling the formation of immune complexes along the glomeruli. Based on this experimental approach, we conclude that metallic ions induce autoimmune nephritis.

\section{Conflict of Interests}

The authors declare that there is no conflict of interests regarding the publication of this paper.

\section{Acknowledgments}

This work was supported by COZCYT-FOMIX Grant ZAC2011-C01-172788 and PROMEP UAZ-CA5 Autoinmunidad.

\section{References}

[1] P. Griem and E. Gleichmann, "Metal ion induced autoimmunity, Current Opinion in Immunology, vol. 7, no. 6, pp. 831-838, 1995.

[2] P. E. Bigazzi, "Metals and kidney autoimmunity," Environmental Health Perspectives, vol. 107, supplement 5, pp. 753-765, 1999.

[3] K. M. Pollard and D. H. Kono, "Requirements for innate immune pathways in environmentally induced autoimmunity," BMC Medicine, vol. 11, no. 1, article 100, 2013.

[4] R. M. Gardner, J. F. Nyland, I. A. Silva, A. Maria Ventura, J. Maria de Souza, and E. K. Silbergeld, "Mercury exposure, serum antinuclear/antinucleolar antibodies, and serum cytokine levels in mining populations in Amazonian Brazil: a cross-sectional study," Environmental Research, vol. 110, no. 4, pp. 345-354, 2010.

[5] S.-J. Li, S.-H. Zhang, H.-P. Chen et al., "Mercury-induced membranous nephropathy: clinical and pathological features," Clinical Journal of the American Society of Nephrology, vol. 5, no. 3, pp. 439-444, 2010.

[6] E. Escudero, A. Martín, M. Nieto et al., "Functional relevance of activated $\beta 1$ integrins in mercury-induced nephritis," Journal of the American Society of Nephrology, vol. 11, no. 6, pp. 1075-1084, 2000.

[7] L. M. Bagenstose, P. Salgame, and M. Monestier, "Murine mercury-induced autoimmunity. A model of chemically related autoimmunity in humans," Immunologic Research, vol. 20, no. 1, pp. 67-78, 1999.

[8] J. J. Bollain-Y-Goytia, M. González-Castañeda, F. Torres-DelMuro et al., "Increased excretion of urinary podocytes in lupus nephritis," Indian Journal of Nephrology, vol. 21, no. 3, pp. 166171, 2011.

[9] O. Mameli, M. A. Caria, F. Melis et al., "Neurotoxic effect of lead at low concentrations," Brain Research Bulletin, vol. 55, no. 2, pp. 269-275, 2001.

[10] P. E. Bigazzi, "Autoimmunity and heavy metals," Lupus, vol. 3, no. 6, pp. 449-453, 1994.

[11] A. Saoudi, M. Castedo, D. Nochy et al., "Self-reactive anti-class II T helper type 2 cell lines derived from gold salt-injected rats trigger B cell polyclonal activation and transfer autoimmunity in CD8-depleted normal syngeneic recipients," European Journal of Immunology, vol. 25, no. 7, pp. 1972-1979, 1995.

[12] P. Hultman, A. Taylor, J. M. Yang, and K. M. Pollard, "The effect of xenobiotic exposure on spontaneous autoimmunity in
(SWR x SJL)F1 hybrid mice," Journal of Toxicology and Environmental Health Part A, vol. 69, no. 6, pp. 505-523, 2006.

[13] U. H. Rudofsky and D. A. Lawrence, "New Zealand mixed mice: a genetic systemic lupus erythematosus model for assessing environmental effects," Environmental Health Perspectives, vol. 107, no. 5, pp. 713-721, 1999.

[14] J. Dressier, K.-A. Kim, T. Chakraborti, and G. Goldstein, "Molecular mechanisms of lead neurotoxicity," Neurochemical Research, vol. 24, no. 4, pp. 595-600, 1999.

[15] P. Hultman and S. Eneström, "Dose-response studies in murine mercury-induced autoimmunity and immune-complex disease," Toxicology and Applied Pharmacology, vol. 113, no. 2, pp. 199-208, 1992.

[16] G. L. Diamond and R. K. Zalups, "Understanding renal toxicity of heavy metals," Toxicologic Pathology, vol. 26, no. 1, pp. 92-103, 1998.

[17] M. M. Yamashita, L. Wesson, G. Eisenman, and D. Eisenberg, "Where metal ions bind in proteins," Proceedings of the National Academy of Sciences of the United States of America, vol. 87, no. 15, pp. 5648-5652, 1990.

[18] B. Rowley and M. Monestier, "Mechanisms of heavy metalinduced autoimmunity," Molecular Immunology, vol. 42, no. 7, pp. 833-838, 2005.

[19] M. Abedi-Valugerdi, C. Nilsson, A. Zargari, F. Gharibdoost, J. W. Depierre, and M. Hassan, "Bacterial lipopolysaccharide both renders resistant mice susceptible to mercury-induced autoimmunity and exacerbates such autoimmunity in susceptible mice," Clinical and Experimental Immunology, vol. 141, no. 2, pp. 238-247, 2005.

[20] K. M. Pollard and G. P. Landberg, "The in vitro proliferation of murine lymphocytes to mercuric chloride is restricted to mature T cells and is interleukin 1 dependent," International Immunopharmacology, vol. 1, no. 3, pp. 581-593, 2001.

[21] S. Havarinasab, K. M. Pollard, and P. Hultman, "Goldand silver-induced murine autoimmunity-requirement for cytokines and CD28 in murine heavy metal-induced autoimmunity," Clinical and Experimental Immunology, vol. 155, no. 3, pp. 567-576, 2009.

[22] V. Jha, C. J. Workman, T. L. McGaha et al., "Lymphocyte activation gene-3 (LAG-3) negatively regulates environmentallyinduced autoimmunity," PLoS ONE, vol. 9, no. 8, p. e104484, 2014. 


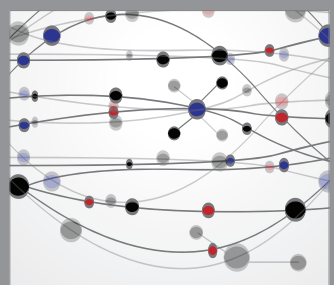

The Scientific World Journal
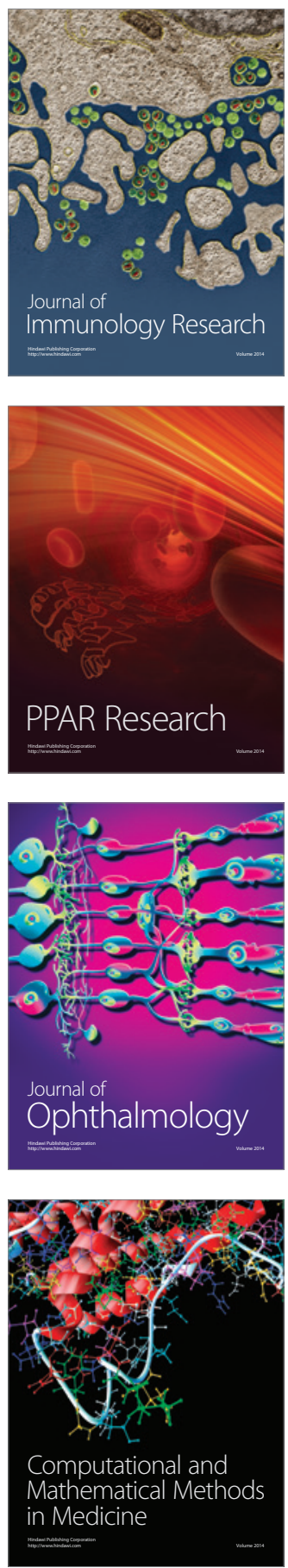

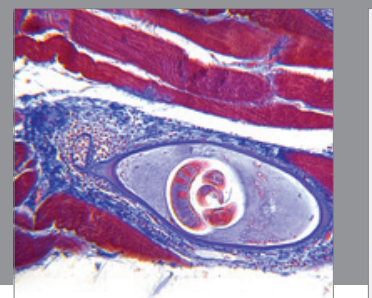

Gastroenterology

Research and Practice
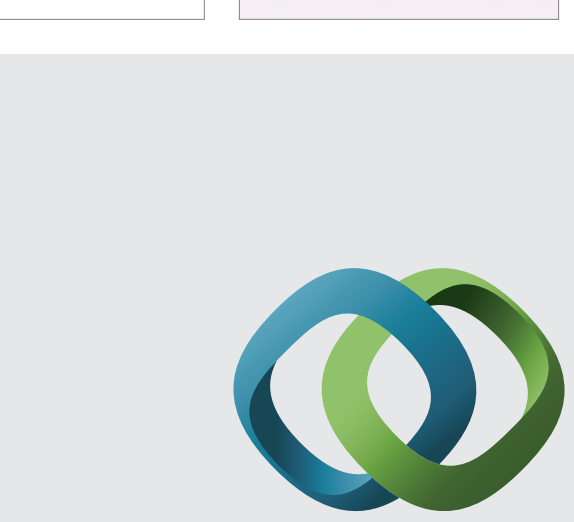

\section{Hindawi}

Submit your manuscripts at

http://www.hindawi.com
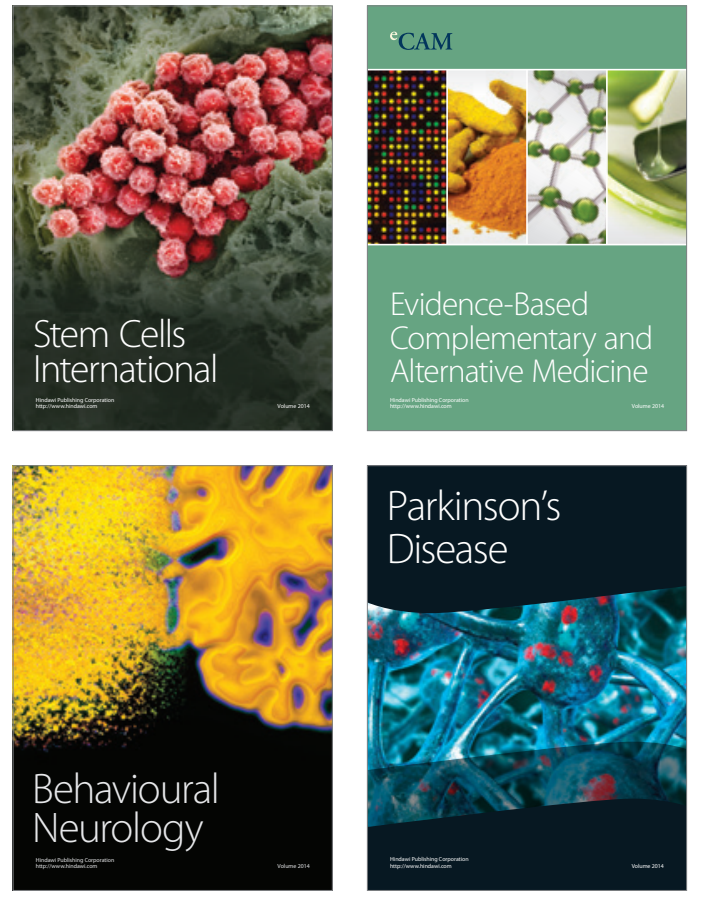
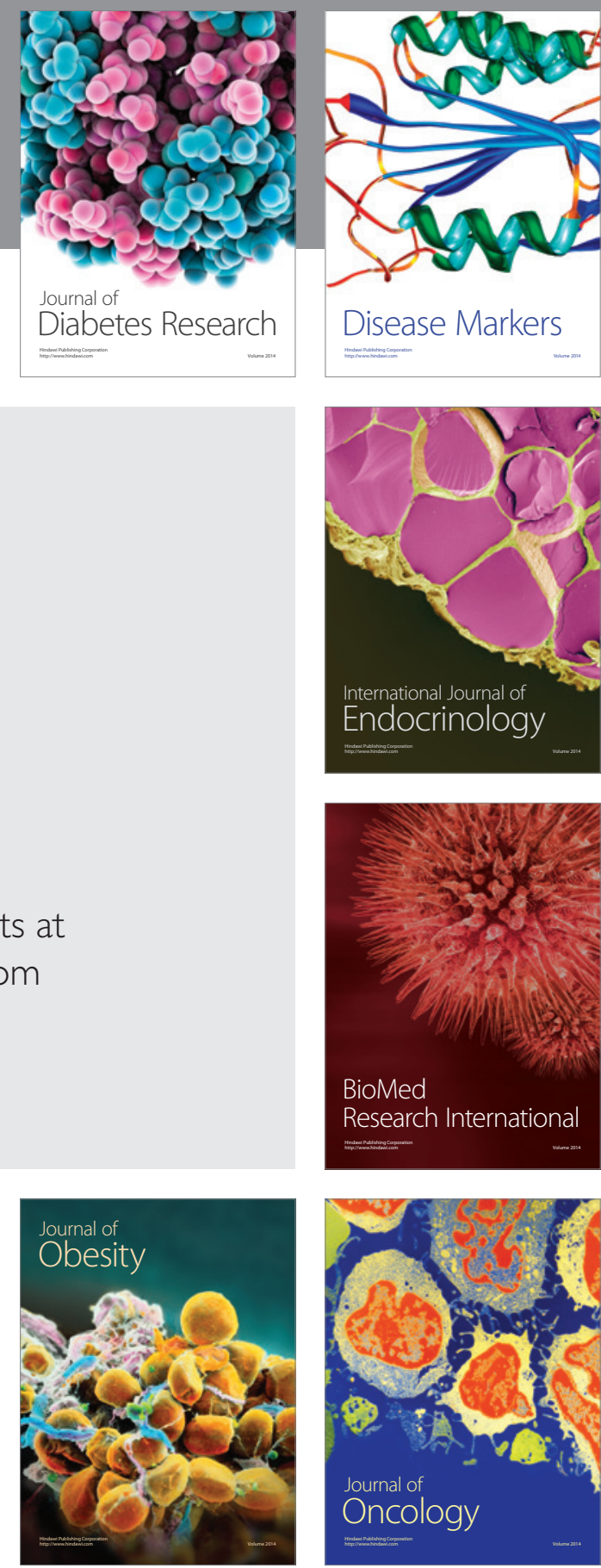

Disease Markers
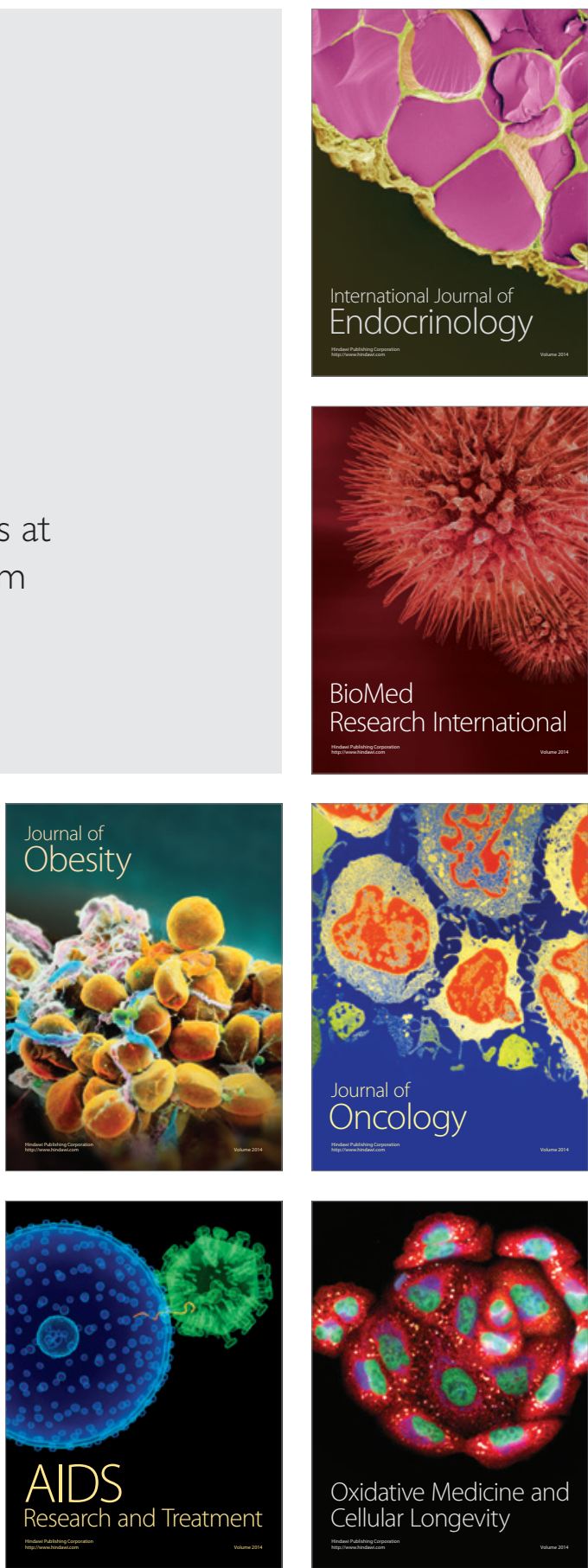